\title{
Radiografía constitucional del principio pro persona
}

\author{
Constitutional X-Ray of Pro Persona Principle
}

\section{Miguel Ángel CóRDOVA*}

RESUMEN: El principio pro persona cambió la manera de interpretar y aplicar los derechos humanos. Esta nueva herramienta permite mejorar la protección de los derechos humanos; sin embargo, la jurisprudencia y la doctrina no han clarificado su estructura ni la manera en cómo funciona. Simplemente la utilizan. En tanto esta situación prevalezca, los límites la jurisprudencia constitucional en materia de derechos humanos serán la discreción y la creatividad de los jueces. Además, la Constitución exige que, en todo momento, las personas reciban la protección más amplia de sus derechos; por ello, esta falta de desarrollo teórico-jurisprudencial constituye un límite a la fuerza vinculante de la Constitución. Por ello, el propósito de este artículo es trazar algunos lineamientos que clarifiquen la estructura normativa del principio pro persona, y la manera en la que puede funcionar para cumplir su propósito constitucional.

Palabras clave: derechos humanos, principios, mandatos de optimización, regla de preferencia de interpretaciones, proporcionalidad.
ABSTRACT: Pro-persona principle changed human rights adjudication and interpretation. This allows judges and lawyers to improve human rights protection; however, case-law and jurisprudence haven't clarified it's structure, and the way it works. They just use it. As long as this situation prevails, the limits of human rights case-law will be judiciary's discretionality and creativity. Besides, the constitution demands to provide, in every moment, the broadest protection to the people's rights; so, this lack of development limits to the constitution's binding force. That's why I will try to draw some guidelines in order to clarify pro-person's principle normative structrure, and the way it may work to fulfill its constitutional purpose.

Keywords: Human Rights, Principles, Optimization Requirements, InterpretationPreference Rule, Proportionality.

* Maestro en Derecho Constitucional y Amparo por la Universidad Cristobal Colón, México. Director de Asuntos Jurídicos de la Comisión Estatal de Derechos Humanos de Veracruz, México. Contacto: miguelcordova1992@gmail.com; https://orcid.org/00000002-9157-9630. 
SUMARIO: I. Introducción. II. Construcción de estándares garantistas de derechos humanos. III. Interpretación extensiva de los derechos humanos. IV Identificación de restricciones ilegítimas a los derechos humanos. V Conclusiones.

\section{INTRODUCCIÓN}

La doctrina concibe al principio pro persona como una espada de dos filos; es decir, como una herramienta que amplía la protección de los derechos humanos y minimiza sus restricciones. ${ }^{1}$

Para ello, funciona como $i$ ) regla de preferencia de interpretaciones, y ii) regla de preferencia de normas. En efecto, si una norma admite varias interpretaciones, se debe escoger la versión más protectora; o, si hay varias normas aplicables, deberá seleccionarse la que proteja mejor a la persona. $^{2}$

En México, el principio pro persona encuentra sustento normativo en el segundo párrafo del artículo 1o. de la Constitución Política de los Estados Unidos Mexicanos (CPEUM). Éste dispone que "[1] as normas relativas a los derechos humanos se interpretarán de conformidad con esta Constitución y con los tratados internacionales de la materia favoreciendo en todo tiempo a las personas la protección más amplia”. De esta disposición se desprenden la cláusula de interpretación conforme y el principio pro persona, pero en este artículo sólo me ocuparé del último.

Para determinar el alcance normativo de una disposición, las reglas de interpretación jurídica recomiendan que el texto de la norma sea el punto de partida de la labor interpretativa. ${ }^{3}$ Por ello, propongo una suerte de

\footnotetext{
1 "Opinión separada del juez Rodolfo Piza Escalante", en Corte IDH, Exigibilidad del derecho de rectificación o respuesta (Arts. 14.1, 1.1 y 2 Convención Americana sobre Derechos Humanos). Opinión Consultiva OC-7/86 de 29 de agosto de 1986, serie A, núm. 7, párr. 36; Pinto, Mónica, "El principio pro homine. Criterios de hermenéutica y pautas para la regulación de los derechos humanos", en Abregú, Martín y Courtis, Christian (comps.), La aplicación de los tratados sobre derechos humanos por los tribunales locales, Buenos Aires, Centro de Estudios Legales y Sociales-Editores del Puerto, 1997.

2 Sagüés, Néstor Pedro, La interpretación judicial de la Constitución, 2a. ed., México, Porrúa-Instituto Mexicano de Derecho Procesal Constitucional, 2016, pp. 316 y ss.

3 Barak, Aharon, Interpretation in Law, 2a. ed., Nueva Jersey, Princeton University Press, 2005, p. 7; Scalia, Antonin y Garner, Bryan, Reading Law. The Interpretation of Legal Texts, St. Paul, Thomson-West, 2012, pp. 56 y ss; Breyer, Stephen, Cómo hacer 
radiografía constitucional de la disposición citada, que dé cuenta de los presupuestos teóricos y la naturaleza del principio pro persona.

La idea es aportar elementos que den claridad respecto a los alcances del principio pro persona como herramienta de protección de los derechos humanos. ¿Qué es lo que los operadores jurídicos pueden hacer con él? ¿Qué significa favorecer con la protección más amplia? ¿Qué es lo que hay que hacer para cumplir con esa disposición constitucional?

Responder esas interrogantes puede evitar que, éste se convierta en una fórmula vacía, endeble, llena de buenas intenciones, pero modulada a voluntad para legitimar decisiones públicas. ${ }^{4}$

Para ello, no voy a tratar de reconstruir el debate teórico-jurisprudencial en torno al principio pro persona. ${ }^{5}$ Tampoco voy a tratar de dar cuenta de las distintas posiciones teóricas en torno al principio pro persona. El propósito de este artículo es proponer una lectura de la expresión "favoreciendo en todo tiempo a las personas la protección más amplia" como un mandato de optimización de los derechos humanos que reconoce el orden jurídico mexicano.

De inicio, mi propuesta puede parecer restrictiva, pero, en el fondo, no lo es. De hecho, permite elaborar un bosquejo de teoría constitucional de los derechos humanos para: i) construir estándares de protección más

funcionar nuestra democracia, trad. de Alfredo Gutiérrez Ortiz Mena, México, Fondo de Cultura Económica, 2017, p. 164.

4 Caballero Ochoa, José Luis y García Huerta, Daniel Antonio, "El principio pro persona en el marco del sistema de interpretación sobre los derechos humanos en México", en Ferrer Mac-Gregor, Eduardo (coord.), Derecho procesal constitucional transnacional. Interacción entre el derecho nacional y el internacional, México, Porrúa-Instituto Mexicano de Derecho Procesal Constitutional, 2016, p. 59.

5 Al respecto, véase Castilla, Karlos, "El principio pro persona en la administración de justicia", Cuestiones Constitucionales, México, núm. 20, enero-junio de 2009, pp. 71 y ss; Caballero Ochoa, José Luis, "La cláusula de interpretación conforme y el principio pro persona (artículo 1o., segundo párrafo, de la Constitución)”, en Carbonell, Miguel y Salazar Ugarte, Pedro (coords.), La reforma constitucional de derechos humanos: un nuevo paradigma, México, UNAM, 2011, pp. 130 y ss; Silva García, Fernando y Gómez Sámano, José Sebastián, "Principio pro homine $v s$. restricciones constitucionales ¿Es posible constitucionalizar el autoritarismo?", en Carbonell, Miguel et al (coords.), Estado constitucional, derechos humanos, justicia y vida universitaria, t. IV, vol. 2, México, UNAM, 2015, pp. 701 y ss; Rodiles, Alejandro, "The Law and Politics of the Pro Persona Principle", en Aust, Helmut Philipp y Nolte, George (eds.), The Interpretation of International Law by Domestic Courts, Nueva York, Oxford University Press, 2016, pp. 163 y ss; Rodarte Berbera, Hayde, "The Pro Personae Principle and its Application by Mexican Courts", Queen Mary Human Rights Law Review, vol. 4, 2018, pp. 3 y ss. 
amplios; ii) interpretar extensivamente los derechos, y iii) identificar si los límites impuestos a un derecho son legítimos.

\section{CONSTRUCCIÓN DE ESTÁNDARES AMPLIOS DE PROTECCIÓN A DERECHOS HUMANOS}

En la jurisdicción nacional casi siempre hay más de disposición de derechos humanos aplicable. Están las normas de fuente constitucional y las de fuente internacional; y entre éstas últimas se encuentran las que pertenecen al sistema universal de protección a derechos humanos y las que pertenecen al sistema interamericano. ${ }^{6} \mathrm{~A}$ su vez, cada una de éstas puede tener más de una interpretación posible.

La primera sala sostiene que, cuando esto sucede, la disposición aplicable es la que otorgue una mayor protección a la persona. ${ }^{7}$ Sin embargo, este criterio no resuelve los escenarios que se presentan cuando las conductas protegidas por las disposiciones de derechos humanos concurrentes sean las mismas, pero con alcances distintos, o con distintos niveles de detalle. Por ello, aun cuando existan varias disposiciones aplicables, al final el operador sólo aplica una: la que, a su juicio, otorgue la mayor protección.

Así, el operador jurídico está entre la espada y la pared, porque deberá elegir entre una disposición de fuente nacional o uno de fuente internacional. Ello lo conduce a un falso dilema entre las fuentes del derecho y la supremacía constitucional.

Para evitar ese obstáculo, hay que entender el principio pro persona con un alcance más limitado porque no permite al operador elegir normas o interpretaciones, según convenga. De acuerdo con el texto constitucional, su alcance es más restringido pues sólo habilita a construir — vía interpretativa - la protección más amplia, no a elegir qué norma aplicar.

Pero puede suceder - y sucede- que existan varias normas aplicables a un caso, las cuales normalmente tienen alcances distintos según su redacción. Cuando esto pasa, el operador tiene que decidir el caso aplicando una norma, aunque la solución dependerá de cómo se conciba al principio pro persona.

6 SCJN, Contradicción de Tesis 293/2011. Sentencia del Pleno del 3 de septiembre de 2013, M.P. Arturo Zaldívar Lelo de Larrea, p. 35.

7 SCJN, Amparo Directo 28/2010. Sentencia de la Primera Sala del 23 de noviembre de 2011, M.P. Arturo Zaldívar Lelo de Larrea, p. 58. 


\section{La regla de preferencia de normas funciona como un juicio de validez}

Si el principio pro persona funciona como regla de preferencia de normas, el operador aplicará la norma "más favorable" y desplazará las demás. Esto presupone que existan más de dos disposiciones aplicables, que regulan el mismo derecho. Si éstas tienen la misma fuente - dos normas de fuente constitucional o dos normas de fuente internacional-, el problema puede resolverse por vía interpretativa.

Pero si hay al menos una norma de fuente constitucional, y al menos una de fuente internacional, la coyuntura se resuelve mediante un juicio de validez.

Aquí no se aplica la norma más protectora. De hecho, se resuelve como si fuera una antinomia mediante el criterio jerárquico, por considerar inviable que un derecho de fuente internacional rebase los límites que la Constitución establece a los derechos humanos. ${ }^{8}$ Así, esta concepción asume que, cuando hay dos o más normas de distinta fuente que regulan un mismo derecho, pero con distintos alcances, estamos en presencia de una antinomia. ${ }^{9}$

Una antinomia existe si hay incompatibilidad entre una norma inferior y una norma superior $;{ }^{10}$ o cuando se imputan consecuencias jurídicas incompatibles a los mismos hechos. ${ }^{11}$ Así, considerar que existe una antinomia cuando hay dos o más normas que regulan un mismo derecho pero con distintos alcances es un artificio, por no decir un error.

8 Véase "Voto particular del señor ministro Luis María Aguilar Morales" y "Voto concurrente del señor ministro Jorge Mario Pardo Rebolledo" en SCJN, Contradicción de Tesis 293/2011, cit. Robert Alexy señala que este es el método para solucionar conflictos de compatibilidad entre normas que son reglas; de este modo, una de las reglas no se aplica por ser inválida. Pero si los derechos humanos se conciben como reglas, y se desaplican por ser inválidos — por cualquier razón_-, se menoscaba su fuerza normativa.

En efecto, "a diferencia de lo que sucede con el concepto de validez social o de la importancia de una norma, el concepto de validez jurídica no es graduable". Alexy, Robert, Teoría de los derechos fundamentales, 2a. ed., trad. de Carlos Bernal Pulido, Madrid, Centro de Estudios Políticos y Constitucionales, 2012, p. 69.

9 Silva Meza, Juan y Silva García, Fernando, Derechos Fundamentales, 2a. ed., México, Porrúa, 2013, pp. 331 y 332.

10 Ferrajoli, Luigi, La democracia a través de los derechos, trad. de Perfecto Andrés Ibañez, Madrid, Trotta, 2014, p. 65.

11 Prieto Sanchís, Luis, Justicia constitucional y derechos fundamentales, 2a. ed., Madrid, Trotta, 2009, p. 175. 
Por ello, no se puede considerar que el principio pro persona resuelva conflictos normativos. Si dos normas regulan la misma conducta, pero con distintos alcances, no hay consecuencias jurídicas incompatibles. Sólo conductas jurídicas distintas — no mutuamente excluyentes - que deben armonizarse por la vía interpretativa.

De allí que, la función del principio pro persona sea construir la versión más favorable del derecho humano en cuestión a la luz de las disposiciones aplicables al caso concreto. No nos dice si una disposición es válida o no; sólo guía la interpretación de las normas aplicables.

\section{La regla de preferencia de interpretaciones} permite ampliar la protección del derecho

Por otro lado, si el principio pro persona opera como regla de preferencia de interpretaciones las consecuencias son distintas. Desde esta perspectiva, los ejercicios comparativos son útiles para resaltar aspectos particulares de la regulación de un derecho desde distintas fuentes; sin embargo, este método no puede emplearse para construir criterios restrictivos. $^{12}$

Justamente, en la Acción de Inconstitucionalidad 155/2007, la Suprema Corte de Justicia de la Nación (SCJN) interpretó la libertad de trabajo para decidir si una norma era constitucional a la luz de varias disposiciones de derechos humanos con alcances distintos. ${ }^{13}$

E1 Pleno resaltó que los instrumentos que protegen la libertad de trabajo en México proscriben el trabajo forzado; es decir, mientras que la Constitución habilita a la autoridad judicial y a la administrativa para establecerlos a título de sanción, los tratados internacionales limitan esa posibilidad a la autoridad judicial.

Por lo tanto no existe contradicción entre la Constitución y los tratados. La única diferencia está en el alcance de la protección que otorgan a la libertad de trabajo.

12 Corte IDH, La colegiación obligatoria de periodistas (artículos 13 y 29 Convención Americana sobre Derechos Humanos). Opinión Consultiva OC-5/85 del 13 de noviembre de 1985, serie A, núm. 5, párr. 51; Caso Trabajadores de la Hacienda Brasil Verde Vs. Brasil. Excepciones preliminares, fondo, reparaciones y costas. Sentencia del 20 de octubre de 2016, serie C, núm. 318, párrs. 310-312.

13 La Suprema Corte valoró el Convenio 29 de la OIT, el Pacto Internacional de Derechos Civiles y Políticos, y la Convención Americana sobre Derechos Humanos. 
No obstante, el principio pro persona obliga a la SCJN a maximizar la protección de los derechos humanos. Así, cuando determina su alcance, no puede interpretarlos a la luz del criterio jerárquico, sino que siempre debe favorecer a la persona con la protección más amplia. ${ }^{14}$ De modo que, aunque el alcance protector varíe entre distintos instrumentos, el operador debe interpretar ampliamente todas las disposiciones que regulen ese derecho y no limitarse a lo que establece al texto constitucional. ${ }^{15}$

Por ello, para otorgar la protección más amplia, el Pleno decidió que los trabajos forzados son una restricción legítima a la libertad de trabajo, pero sólo cuando éstos son consecuencia de una sanción impuesta por un juez.

Así, las normas constitucionales no limitan un derecho cuando lo protegen con un alcance menor que una norma de fuente internacional, sino que - en cualquier caso - establecen modificadores internos para guiar su interpretación. ${ }^{16}$ De esta forma, la regla de preferencia de interpretaciones permite construir estándares de protección de derechos humanos más amplios, y con un alcance mayor que el sugerido por la literalidad de la constitución. ${ }^{17}$

\section{INTERPRETACIÓN EXTENSIVA DE LOS DERECHOS HUMANOS}

\section{El principio pro persona convierte a los derechos humanos en principios (mandatos de optimización)}

La regla de preferencia de interpretaciones permite beneficiar a las personas, en todo momento, con la protección más amplia. Para cumplir con

14 SCJN, Acción de Inconstitucionalidad 155/2007. Sentencia del Pleno del 7 de febrero de 2012, M.P. Sergio Salvador Aguirre Anguiano, pp. 23 y 24.

15 Ibidem, p. 26.

16 Barak, Aharon, Proportionality: Constitutional Rights and their Limitations, trad. de Doron Kalir, Nueva York, Cambridge University Press, 2012, pp. 33; Gardbaum, Stephen, "Limiting Constitutional Rights", UCLA Law Review, Los Angeles, núm. 54, 2007, pp. 801 y ss.; Kumm, Mattias, "Political Liberalism and the Structure of Rights: on the Place and Limits of the Proportionality Requierement", en Pavlakos, George (ed.), Law, Rights and Discourse: The Legal Philosphy of Robert Alexy, Cornwall, Hart Publishing, 2007, pp. 131 y ss.

17 Solum, Lawrence B., "The interpretation-construction distinction”, Constitutional Commentary, Minnesota, núm. 27, núm. 1, 2010.

Esta obra está bajo una Licencia Creative Commons Atribución-NoComercial-SinDerivar 4.0 Internacional, IIJ-UNAM. 
esta exigencia constitucional, la interpretación de los derechos humanos debe hacerse en dos etapas.

Este método determina con mayor claridad el alcance normativo de los derechos humanos, y los bienes constitucionalmente protegidos, que están en juego en un caso concreto. Esto facilita maximizar su eficacia cuando entran en pugna a la luz de ciertos hechos, o al momento de determinar su contenido y alcance. En otras palabras, el método de dos etapas propicia la optimización de los derechos humanos.

En la primera se determina el contenido previo o prima facie del derecho; es decir, se consideran todas las conductas que un derecho humano protege, y lo que el Estado debe hacer o dejar de hacer para respetarlo y garantizarlo, sin considerar sus límites. ${ }^{18}$

No se trata de imaginar todas las conductas que el derecho interpretado podría proteger. Esa tarea es prácticamente imposible. El punto es englobar todos los escenarios ya conocidos o explorados - por la jurisprudencia o la doctrina - en los que el derecho interpretado despliega sus efectos protectores, sin excluir a priori algún escenario o alguna conducta.

En la segunda, se aplica esta visión amplia del derecho y se delimita en relación con los hechos y con los bienes jurídicos relevantes del caso. ${ }^{19}$ Sobre esto me referiré más adelante, por ahora basta señalar que esta visión nos acerca a la teoría de los principios de Robert Alexy.

De acuerdo con el profesor Alexy, los principios son mandatos de optimización que ordenan que algo se realice en la mayor medida posible, de acuerdo con las situaciones fácticas y jurídicas relevantes. ${ }^{20}$ Es decir, son normas que - por su naturaleza - deben interpretarse extensivamente.

A la luz de la teoría de Alexy, el principio pro persona convierte a los derechos humanos en principios que, en cada caso, deben optimizarse. Esta perspectiva dota a la interpretación de los derechos humanos de una estructura argumentativa que facilita su aplicación y maximiza sus efectos protectores.

18 Barak, Aharon, Proportionality..., cit., p. 19; Silva Meza, Juan y Silva García, Fernando, op. cit., p. 128.

19 Barak, Aharon, Proportionality..., cit., p. 19; SCJN, Amparo en Revisión 237/2014. Sentencia de la Primera Sala del 4 de noviembre de 2015, M.P. Arturo Zaldívar Lelo de Larrea, p. 29; Amparo en revisión 208/2016. Sentencia de la Primera Sala del 19 de octubre de 2016, M.P. Arturo Zaldívar Lelo de Larrea, p. 14.

20 Alexy, Robert, op. cit., p. 67; Klatt, Matthias y Meister, Moritz, The Constitutional Structure of Proportionality, Oxford, Oxford University Press, 2012, p. 10. 


\section{El método de dos etapas permite favorecer a la persona con la protección más amplia}

Favorecer a las personas con la protección más amplia requiere interpretar extensivamente las disposiciones que reconocen derechos humanos. Riccardo Guastini afirma que el efecto de este método de interpretación es reducir la indeterminación de las disposiciones normativas, mediante la aplicación de la norma a los casos dudosos. ${ }^{21}$

Para ello, la interpretación se debe hacer en dos etapas. ${ }^{22}$ La primera determina el contenido prima facie o previo del derecho (en lo sucesivo, me referiré al derecho humano que es objeto de interpretación pro persona como D1). Éste no varía caso a caso, porque las conductas que protege no dependen de las variables fácticas y jurídicas del caso concreto, sino del texto de la norma que dispone a D1. Por ello, el contenido previo es abstracto, amplio, y en consecuencia previsible y determinado con mayor certeza en el futuro. ${ }^{23}$

En esta etapa es común preguntarse si una conducta entra o no en el ámbito de protección de un derecho. Esto obedece a que todas las normas tienen zona de certeza y una zona de penumbra. La zona de certeza abarca los escenarios claramente regulados por la norma, de modo que el caso es subsumible en la norma, porque no hay problemas de vaguedad, ambigüedad, o de valoración de los términos usados por el legislador que dificulten el proceso de interpretación. ${ }^{24}$

La zona de penumbra comprende todos los supuestos que no entran en la zona de certeza. Aquí, los problemas de vaguedad, ambigüedad o de valoración de los términos usados por el legislador impiden determinar si el caso entra en el campo de aplicación de la norma o no. ${ }^{25}$

21 Guastini, Riccardo, Interpretar y argumentar, trad. de Silvia Álvarez Medina, Madrid, Centro de Estudios Políticos y Constitucionales, 2017, pp. 112 y 113.

22 Weinrib, Lorraine E., "The Postwar Paradigm and American exceptionalism", en Choudhry, Sujit (ed.), The Migration of Constitutional Ideas, Nueva York, Cambridge University Press, 2006, p. 93.

23 Klatt, Matthias y Mesiter, Moritz, La proporcionalidad como principio constitucional universal, México, UNAM, Instituto de Investigaciones Jurídicas, 2017, p. 52.

24 Nino, Carlos Santiago, Fundamentos de Derecho Constitucional, Buenos Aires, Astrea, 1992, pp. 84 y ss; Bernal Pulido, Carlos, El principio de proporcionalidad y los derechos fundamentales, 4a. ed., Bogotá, Universidad Externado de Colombia, 2014, pp. 126 y ss.

25 Hart, H. L. A., "Positivism and the Separation of Law and Morals", Harvard Law Review, vol. 71, núm. 4, 1958, pp. 607 y ss.

Esta obra está bajo una Licencia Creative Commons Atribución-NoComercial-SinDerivar 4.0 Internacional, IIJ-UNAM. 
En ese sentido, el principio pro persona arroja luz sobre la zona de penumbra porque obliga al operador a decidirse por ampliar el contenido del derecho cuando existen dudas sobre si éste protege o no una conducta.

La segunda etapa delimita el contenido definitivo del derecho. Este contorno es el resultado de la interacción de D1 con otros bienes jurídicos - como los derechos humanos de otras personas u otros bienes constitucionalmente protegidos (a éstos me referiré en lo sucesivo como D2 y BC, respectivamente) - en un caso concreto.

D2 y BC funcionan como límites externos a D1 en tanto que no forman parte de éste, sino que operan como tales en función de la forma en la que se relacionen en el contexto del caso concreto. ${ }^{26}$ Esta idea la desarrollaré más ampliamente en los siguientes apartados; por ahora basta con precisar que de las relaciones de D1 con D2 y BC depende que el contenido de D1 opere a plenitud o resulte limitado por el alcance de éstos últimos.

Si D2 o BC no inciden en el contenido previo de D1, el contenido definitivo será equivalente al contenido previo; pero si D2 o BC inciden en el contenido previo, entonces el contenido definitivo tendrá un alcance menor por estar delimitado por los otros bienes constitucionales en juego en ese caso concreto. El grado de intervención al contenido de D1 debe analizarse a la luz del principio de proporcionalidad para determinar si éste es constitucional o no. ${ }^{27}$

El resultado de este ejercicio interpretativo es el contenido definitivo del derecho humano, a la luz del caso concreto. ${ }^{28}$

De este modo es posible cumplir con la exigencia constitucional de favorecer a las personas, en todo momento, con la protección más amplia. Primero, se interpretan extensivamente los derechos humanos, y luego acomoda esta visión a las circunstancias jurídicas y fácticas relevantes de cada caso. $^{29}$

Aharon Barak sostiene que este método maximiza la eficacia de los derechos humanos porque distingue entre el alcance abstracto del dere-

26 SCJN, Amparo en Revisión 237/2014, cit., p. 42; Prieto Sanchís, Luis, op. cit., pp. 222 y ss; Gardbaum, Stephen, op. cit., p. 801.

27 Barak, Aharon, Proportionality..., cit.; Klatt, Matthias y Meister, Moritz, op. cit.; Bernal Pulido, Carlos, op. cit.

28 La Primera Sala de la SCJN utilizó este método para determinar la constitucionalidad del uso lúdico de la marihuana y de la libertad de los padres de decidir el orden de los apellidos de sus hijos. SCJN, Amparo en revisión 237/2014, cit.; Amparo en Revisión 208/2016, cit.

29 Klatt, Matthias y Mesiter, Moritz, op. cit., p. 52.

Esta obra está bajo una Licencia Creative Commons

Atribución-NoComercial-SinDerivar 4.0 Internacional, IIJ-UNAM. 
cho humano y su ámbito específico de protección - contenido previo y contenido definitivo, respectivamente- Esta operación delimita las circunstancias en las que opera - y no opera - la protección constitucional de un derecho; los sujetos que están obligados a protegerlo; y los actos prohibidos o permitidos en relación con el contenido del derecho. ${ }^{30}$

Además, esta distinción permite ganar claridad expositiva. En el mejor de los casos, si esto se olvida — o se pasa por alto - la argumentación se vuelve desestructurada, opaca, y confunde el contenido de los derechos y sus restricciones. ${ }^{31}$ En el peor de los casos, la mala interpretación de un derecho puede cercenar su alcance y hacerlo ilusorio.

\section{Primera etapa: el alcance máximo del derecho}

humano se determina en abstracto

La primera etapa ocurre a nivel constitucional. Aquí se determina el alcance de D1, las conductas que protege, y lo que el Estado debe hacer y dejar de hacer para respetarlo y garantizarlo. ${ }^{32}$ Esto puede denominarse contenido prima facie, o contenido previo, porque sólo se enuncian en abstracto las conductas que gozan de protección constitucional - y las que no entran en ese ámbito de protección—, ${ }^{33}$ sin considerar cómo se relacionen con el caso concreto con BC. ${ }^{34}$

El contenido definitivo sí considera los elementos fácticos y jurídicos aplicables al caso, pero esto es relevante hasta la segunda etapa. De este modo, el resultado de la primera etapa es la determinación del contenido total de D1, y no un derecho ya limitado. Serán las circunstancias de cada

30 Alvez, Amaya, “'Made in México? El principio de proporcionalidad adoptado por la Suprema Corte de Justicia de la Nación ¿La migración de un mecanismo constitucional?", Revista de la Facultad de Derecho de México, México, núm. 253, enero-junio de 2010 , p. 365.

31 Klatt, Matthias y Mesiter, Moritz, op. cit., p. 51.

32 Barak, Aharon, Proportionality..., cit., pp. 19 y 20; Silva Meza, Juan y Silva García, Fernando, op. cit., p. 128; SCJN, Amparo en Revisión 237/2014, cit., p. 30.

33 Barak, Aharon, Proportionality..., cit., pp. 19 y 20; Gardbaum, Stephen, op. cit., p. 803 .

34 Schauer, Frederik, "Freedom of Expression Adjudication in Europe and the United States: a Case Study in Comparative Constitutional Architecture", en Nolte, George (ed.), European and US Constitutionalism, Nueva York, Cambridge University Press, 2005, p. 69. 
caso las que determinen sus límites y su contenido definitivo, no su interpretación.

El punto de partida de esta etapa es una lectura generosa de la disposición que enuncia D1 para dotarlo del mayor alcance posible. Los límites de ese proceso son las reglas del lenguaje. Así, el resultado de la interpretación no puede exceder los límites fijados por el texto interpretado. ${ }^{35}$

Por ejemplo, la SCJN ha sostenido — en abstracto - que la libertad de expresión protege discursos muy diversos. De tal manera, "el Estado no puede privilegiar un determinado criterio de decencia, estética o decoro respecto a las expresiones que podrían ser bien recibidas, ya que no existen parámetros uniformemente aceptados que puedan delimitar el contenido de estas categorías". ${ }^{36}$ No es que exista un derecho a insultar, pero tampoco pueden prohibirse las expresiones "inusuales, alternativas, indecentes, escandalosas, excéntricas o simplemente contrarias a las creencias y posturas mayoritarias, aún y cuando se expresen acompañadas de expresiones no verbales, sino simbólicas". ${ }^{37}$

En esta etapa pueden advertirse tensiones, o conflictos potenciales, con otros bienes constitucionalmente protegidos - los derechos humanos de otras personas (D2), o principios constitucionales (BC) - ${ }^{38}$ que delimiten el contenido definitivo de D1. Sin embargo, esos conflictos ocurren hasta que D1 entra en relación con los hechos y las normas aplicables al caso, no cuando se le dota de alcance y contenido a través de la interpretación. Por ello, esos conflictos deben solucionarse hasta la segunda etapa.

En D1 debe brillar todo en su esplendor - sin considerar probables conflictos con otros bienes jurídicos como D2 o BC- para determinar correctamente su alcance. ${ }^{39}$

Así, aunque las tensiones ya sean notorias, tratar de conciliarlas prematuramente puede cercenar parcial o totalmente el contenido de D1. Por ejemplo, en el caso González Lluy vs. Ecuador, la víctima —-Talía González Lluy - era una niña que tenía tres años cuando recibió una transfusión

35 Barak, Aharon, Purposive Interpretation..., cit., p. 7; Breyer, Stephen, op. cit., p. 164.

36 SCJN, Amparo Directo 28/2010, cit., p. 75.

37 Idem.

38 Gardbaum, Stephen, op. cit., p. 801; Barak, Aharon, Proportionality..., cit., p. 71; Klatt, Matthias y Meister, Moritz, op. cit., p. 23.

39 Barak, Aharon, Human Dignity: the Constitutional Value and the Constitutional Right, trad. de Daniel Kayros, Nueva York, Cambridge University Press, 2015, p. 134. 
de sangre con VIH. Cuando sus profesores supieron esta circunstancia, Talía fue expulsada de la escuela a la que asistía.

Para garantizar su derecho a la educación, sus familiares recurrieron al amparo constitucional. Sin embargo, los tribunales ecuatorianos avalaron su expulsión bajo el supuesto de poner en riesgo la integridad de sus compañeros. ${ }^{40} \mathrm{La}$ Corte IDH resaltó que considerar en abstracto el interés superior del niño, en favor de los compañeros de Talía, no justificaba privarla del derecho a la educación. ${ }^{41}$

Esto no significa que el interés colectivo y la integridad de los compañeros de Talía no fueran relevantes, o que no merecían consideración alguna. Al contrario, los derechos humanos de otras personas y los principios constitucionales opuestos a D1 siempre deben considerarse, pero hasta la segunda etapa de interpretación. Al valorarlos prematuramente, constituyeron un límite arbitrario a los derechos de Talía, y los volvieron ilusorios.

\section{Segunda etapa: el ámbito especifico de protección del derecho depende de cada caso}

En la segunda etapa se determina el contenido definitivo de D1. Esto obedece a que, una vez que el contenido previo de D1 ha sido determinado, éste entra en contacto con los hechos del caso y los otros bienes jurídicos en juego. ${ }^{42}$ Éstos últimos constituyen los límites externos de D1, porque no son intrínsecos a éste, sino que dependen de la forma en la que se relacione con $\mathrm{D} 2$ o $\mathrm{BC}$ en el caso concreto. ${ }^{43}$

El alcance de los límites externos —D2 o BC — también se delimita vía interpretativa. De tal suerte, en esta etapa hay dos posibilidades: $i$ ) que el alcance de D2 o BC interfiera de alguna forma en el contenido de D1, o ii) que $\mathrm{D} 2$ o $\mathrm{BC}$ no interfieran en el contenido de D1. En el primer caso, el contenido definitivo es idéntico al contenido previo; en el segundo, el contenido definitivo tiene un alcance menor que el contenido previo. ${ }^{44}$

40 Corte IDH, Caso Gonzales Lluy y otros vs. Ecuador. Excepciones preliminares, fondo, reparaciones y costas. Sentencia del 1o. de septiembre de 2015, serie C, núm. 298, párrs. 141 y 142 .

41 Ibidem, párr. 265.

42 SCJN, Amparo en Revisión 237/2014, cit., p. 30.

43 Prieto Sanchís, Luis, op. cit., pp. 222 y ss.; Gardbaum, Stephen, op. cit., p. 801; SCJN, Amparo en Revisión 237/2014, cit., p. 42.

44 Barak, Aharon, Human Dignity..., cit., p. 134.

Esta obra está bajo una Licencia Creative Commons Atribución-NoComercial-SinDerivar 4.0 Internacional, IIJ-UNAM. 
Generalmente, las tensiones entre D1 y D2 o BC se advierten al definir el contenido previo. Pero es hasta aquí cuando cobran relevancia y deben solucionarse, no antes.

La pauta para solucionar esas tensiones son las cláusulas de restricción - generales o específicas- Estas normas no excluyen conductas de la protección de un derecho, sino que determinan los fines o propósitos constitucionalmente legítimos para restringir un derecho - $\mathrm{BC}$ o D2-. ${ }^{45}$ En tal virtud, las cláusulas de restricción orientan el razonamiento del operador porque resaltan los bienes jurídicos que delimitan el contenido definitivo de D1 en un caso concreto. ${ }^{46}$

De tal manera, no cualquier fin legitima la restricción del alcance de un derecho, sino sólo aquellos expresamente previstos por el texto que los enuncia — cláusulas de restricción específicas-, o por el instrumento que los consagra — cláusulas de restricción generales — ${ }^{47}$ En otras palabras, son una suerte de portal que, una vez abierto, permiten la entrada de bienes constitucionalmente protegidos que acotan y delimitan el contenido definitivo del derecho en cuestión.

Por ejemplo, la libertad de expresión no cede ante cualquier propósito enarbolado en abstracto, sólo frente a los fines taxativamente establecidos por la CPEUM y los tratados internacionales. En tal sentido, la Corte IDH sostiene que invocar en abstracto, y sin probar, a un derecho protegido por la Convención Americana sobre Derechos Humanos no legitima la restricción de un derecho. ${ }^{48}$

Lo anterior da cuenta de que las restricciones al ejercicio de los derechos humanos no operan automáticamente. Y es justo aquí donde radica la utilidad del método de dos etapas. Este método de interpretación impide

45 SCJN, Recurso de Revisión en Materia de Seguridad Nacional 1/2015. Sentencia del Pleno del 3 de abril de 2017, M.P. Javier Laynez Potisek, p. 36; Gardbaum, Stephen, op. cit., p. 801.

46 Miller, Bradley W., “Justification and Rights Limitation”, en Huscroft, Grant (ed), Expounding the Constitution, Nueva York, Cambridge University Press, 2010, p. 94.

47 Una interpretación menos nacionalista sugiere que el primer párrafo del artículo 1o. de la CPEUM establece una reserva de Constitución - de modo que la potestad de establecer las condiciones en las que es legítimo limitar el ejercicio de los derechos humanos es exclusiva de la CPEUM - y no que ésta deba prevalecer sobre los derechos humanos de fuente internacional.

48 Corte IDH, Caso Atala Riffo y niñas Vs. Chile. Fondo, reparaciones y costas. Sentencia del 24 de febrero de 2012, serie C, núm. 239, párr. 110; Weinrib, Lorraine E., op. cit., p. 96. 
que la consideración prematura de otros bienes jurídicos relevantes cercene la protección constitucional a conductas que se encuentran dentro del alcance de D1.

Ciertamente, al determinar el contenido previo de D1 en abstracto es posible vislumbrarlo completamente antes de aplicarlo al caso. Éste no llega mutilado a la etapa aplicativa - como sucedió en el caso de González Lluy_, sino que se confronta a los factores jurídicos relevantes. Éstos pueden o no incidir en ese alcance; si no inciden, y las tensiones son aparentes, el contenido previo del derecho en cuestión opera a plenitud en ese caso. Pero si la tensión es real y limita el contenido previo del derecho, el grado de afectación y su justificación debe analizarse a la luz del juicio de proporcionalidad.

\section{El principio pro persona en acción}

Recientemente, la Primera Sala de la SCJN determinó que el derecho a la vida privada familiar y la libertad religiosa no protegen la posibilidad de privar a una niña de un tratamiento médico adecuado, aunque ello contravenga las creencias religiosas de sus padres. Especialmente si ello implica riegos para su salud o su propia vida. ${ }^{49}$

El ejemplo se trata de un asunto controversial. Una niña - la SCJN la denomina "Clara" en la versión pública de la sentencia- padecía leucemia linfoblástica aguda y sus padres son Testigos de Jehová. De acuerdo con el diagnóstico médico, el tratamiento idóneo era la aplicación de quimioterapias acompañadas de transfusiones sanguíneas; sin embargo, sus padres solicitaron un tratamiento alternativo porque las transfusiones contravienen sus creencias religiosas. ${ }^{50}$

El tratamiento alternativo implicaba el uso de hemoderivados para asegurar que la atención médica no transgrediera los preceptos religiosos de los Testigos de Jehová. ${ }^{51}$ No obstante, dada la condición de Clara, el uso de hemoderivados no garantizaba su recuperación e incluso ponía en riesgo su vida. ${ }^{52}$

49 SCJN, Amparo en Revisión 1049/2017. Sentencia de la Primera Sala del 15 de agosto de 2018, M.P. Arturo Zaldívar Lelo de Larrea, pp. 48 y ss.

50 Ibidem, pp. 21 y 22.

51 Ibidem, p. 42.

52 Ibidem, p. 55. 
Por lo anterior, y frente a la negativa de los padres de Clara a utilizar el tratamiento idóneo, las autoridades hospitalarias solicitaron la intervención de la Subprocuraduría de Protección Auxiliar de Niñas, Niños y Adolescentes del Distrito Judicial de Morelos, Chihuahua (en adelante, la Subprocuraduría). Al enterarse de la situación, la Subprocuraduría tomó la representación de Clara en suplencia de sus padres y autorizó el tratamiento propuesto por los médicos. ${ }^{53}$

Para sostener su decisión, la Primera Sala utilizó el método de dos etapas - aunque no explícitamente - para delimitar con mucha claridad los bienes jurídicos en juego, a saber: $i$ ) el derecho a la vida privada familiar; ii) la libertad religiosa de los padres de Clara; iii) el interés superior de Clara, y iv) su derecho a la vida y a la salud.

En esa tesitura, la Primera Sala utiliza una concepción principialista de los derechos humanos para delimitar sus alcances, y maximizar la protección de los bienes jurídicos en juego. Es decir, les da el mayor alcance posible en abstracto, para luego determinar su alcance definitivo a la luz de todos los elementos fácticos y jurídicos relevantes del caso.

Vale decir que la concepción principialista de los derechos humanos no necesariamente - o no solamente - se expresa a través del juicio de proporcionalidad. También tiene una dimensión interpretativa que no determina la validez o aplicabilidad de los principios, sino su alcance normativo. ${ }^{54}$ Esta es la vertiente de la teoría de los principios empleada por la Primera Sala en este caso.

En este sentido, la SCJN interpretó en abstracto el derecho a la vida privada familiar de los padres de Clara, y sostuvo que ésta merece protección frente a las intrusiones del Estado, en tanto que los padres son quienes se encuentran más aptos para tomar decisiones sobre sus hijos. ${ }^{55}$ Esto implica la libertad de inculcarles las creencias religiosas que estimen más convenientes $;{ }^{56} \mathrm{y}$ de tomar decisiones médicas por ellos. ${ }^{57}$

Pese a lo anterior, el margen de los padres para decidir sobre la vida de sus hijos no es absoluto. El límite de ese margen es el interés superior del menor. Conforme a éste, los actos de la autoridad deben preservar y

\footnotetext{
53 Idem.

54 Barak, Aharon, Proportionality..., cit., pp. 92 y 93.

55 SCJN, Amparo en Revisión 1049/2017, cit., p. 24.

56 Ibidem, pp. 25 y ss.

57 Ibidem, pp. 31 y ss.
}

Esta obra está bajo una Licencia Creative Commons

Atribución-NoComercial-SinDerivar 4.0 Internacional, IIJ-UNAM. 
satisfacer los mejores intereses de los niños, y los padres deben adoptarlo como el eje rector para decidir en nombre de sus hijos. ${ }^{58}$ Así, los padres deben ejercer sus derechos mirando siempre por el bienestar de sus hijos.

De tal suerte, "los derechos parentales" no constituyen un valor preponderante. En efecto, la primera sala afirmó que

[L]os padres gozan con un ámbito de autonomía muy amplio para tomar numerosas decisiones por sus hijos - a qué escuela van a acudir, en donde deciden vivir, qué valores inculcar y qué religión enseñarles-, y autonomía para sopesar diversas razones y elegir lo que estimen mejor para ellos sin intervenciones externas. En ese sentido, el derecho presume que son los más aptos para decidir lo que resulte más favorable para las niñas y niños a su cargo.

Sin embargo, el interés superior del menor es una consideración prevalente tratándose de decisiones que son críticas para el futuro o bienestar de un menor, como aquellas relacionadas con su derecho a la salud y a la vida. En ese sentido, esta Corte entiende que el derecho de los padres a tomar esas decisiones sin interferencias encuentra su límite en la salud y la vida del menor.

En efecto, esta Primera Sala entiende que las decisiones médicas de los padres sobre sus hijos, aunque inicialmente protegidas por un campo de autonomía, no pueden ser sostenidas si colocan en riesgo la salud del menor (aun cuando esta no sea necesariamente la intención de los padres). En tanto la Constitución obliga al Estado a velar por que no se vulneren los derechos de los niños, en estos casos está justificado intervenir en la autonomía familiar con el objeto de impedir una afectación a la integridad del menor. ${ }^{59}$

El riesgo para la integridad de Clara se actualizó cuando sus padres privilegiaron sus creencias religiosas y se rehusaron a seguir el tratamiento médico idóneo para salvar la vida de su hija. ${ }^{60}$ Incluso si desde su cosmovisión ellos velaban por los mejores intereses de su hija, obstaculizar o impedir la aplicación de un tratamiento médico a un menor porque contraviene las creencias religiosas de sus padres no es una conducta protegida por el derecho a la vida privada familiar, ni por el derecho a la libertad

\footnotetext{
58 Ibidem, p. 35.

59 Ibidem, p. 37

60 Ibidem, p. 40.
} 
religiosa. Esto obedece a que la vida de los hijos no es un bien jurídico del que puedan disponer los padres. ${ }^{61}$

La interpretación que hizo la Primera Sala de los derechos en juego determinó su alcance. Primero en abstracto, al margen de las consideraciones del caso; y después en concreto, a la luz de los hechos y de los otros bienes jurídicos en juego.

Esto le permitió concluir que la intervención de la Subprocuraduría no interfirió los derechos humanos de los padres de Clara. Por ello no fue necesario analizar la intervención a la luz del principio de proporcionalidad. Sin embargo, la Primera Sala sí realizó un control de legalidad y constitucionalidad de la actuación de la Subprocuraduría para verificar que ésta se limitara a garantizar la salud de Clara, y no desplazara por completo los derechos de sus padres. ${ }^{62}$

\section{IDENTIFICACIÓN DE RESTRICCIONES ILEGÍTIMAS}

\section{A LOS DERECHOS HUMANOS}

La doctrina y jurisprudencia comparada aceptan pacíficamente que, en ciertas condiciones, es legítimo restringir los derechos humanos. ${ }^{63}$ Sin embargo, en México es un asunto espinoso desde que la SCJN resolvió la contradicción de tesis 293/2011. ${ }^{64}$

La decisión es problemática porque el Pleno sostuvo que todos los derechos humanos integran el parámetro de control de regularidad constitucional; ${ }^{65}$ pero cuando exista una restricción constitucional al ejercicio de un derecho, deberá preferirse aplicarse la restricción y no el derecho humano. ${ }^{66}$

\footnotetext{
61 Ibidem, p. 43.

62 Ibidem, pp. 44 y ss.

63 Prieto Sanchís, Luis, op. cit., p. 217.
}

64 Véase "Voto particular que formula el Ministro Arturo Zaldívar Lelo de Larrea", en SCJN, Recurso de revisión en materia de seguridad nacional 1/2015, cit., p. 6. En su voto, el Ministro Zaldívar afirma que el concepto de "restricciones" a los derechos humanos suscita discusiones y desacuerdos en la jurisprudencia constitucional de la SCJN.

65 "[U]na de las principales aportaciones de la reforma constitucional es la creación de un conjunto de normas de derechos humanos, cuya fuente puede ser, indistintamente, la Constitución o un tratado internacional. Así, este conjunto integra el nuevo parámetro de control de regularidad o validez de las normas del ordenamiento jurídico mexicano". SCJN, Contradicción de tesis 293/2011, cit., p. 30.

66 "[D]erivado de la parte final del primer párrafo del artículo $1^{\circ}$ constitucional, el 
En buena parte, este debate se debe a que el concepto de restricciones a los derechos humanos no tiene un significado definido en la jurisprudencia constitucional mexicana. Por ello, en la práctica puede abarcar disposiciones que no necesariamente limiten el contenido de un derecho, sino que, por el contrario, sólo excluyen conductas de protección constitucional. ${ }^{67}$ Justamente, el ministro Arturo Zaldívar advierte sobre la ambigüedad que rodea la idea de las restricciones a los derechos humanos. ${ }^{68}$

De tal forma, la decisión del pleno anula al principio pro persona en donde su uso es crítico, porque lo petrifica como una regla de preferencia de normas. En consecuencia, el operador jurídico no puede construir estándares amplios de protección a los derechos humanos, sino que debe elegir entre los derechos de fuente constitucional o los derechos de fuente internacional $;{ }^{69}$ tampoco puede aplicar el método de las dos etapas. Por ello, como sostuve en líneas anteriores, la diferencia en los alcances funciona en la práctica como una antinomia.

Sin embargo, si el principio pro persona se concibe únicamente como regla de preferencia de interpretaciones, la ductibilidad de los principios, y la interpretación en dos etapas permite a los jueces analizar si los límites al ejercicio de un derecho son legítimos a la luz del juicio de proporcionalidad.

\section{El juicio de proporcionalidad impide la aplicabilidad automática de las restricciones constitucionales}

El juicio de proporcionalidad soluciona el dilema de la CT 293/2011 porque no niega la posibilidad de que los derechos puedan limitarse. De hecho, este juicio parte de una lectura principialista de la Constitución y de los derechos humanos, de modo que no niega la posibilidad de limitarlos, sin que eso excluya a su vez el deber de optimizar la protección de esos derechos. ${ }^{70}$

Pleno de esta Suprema Corte de Justicia de la Nación entiende que cuando en la Constitución haya una restricción expresa al ejercicio de los derechos humanos, se deberá estar a lo que indica la norma constitucional". Ibidem, p. 49.

67 Gardbaum, Stephen, op. cit., pp. 803 y ss.

68 Voto aclaratorio y concurrente que formula el Ministro Arturo Zaldívar Lelo de Larrea”, en SCJN, Contradicción de Tesis 293/2011, cit., p. XIV.

69 Cossío Díaz, José Ramón, Voto en contra, México, Debate, 2019, p. 45.

70 Alexy, Robert, El concepto y validez del derecho, 2a. ed., trad. de Jorge M. Seña, 
De este modo, el principio pro persona oxigena la aplicación de límites a los derechos humanos. En efecto, desde el juicio de proporcionalidad puede analizarse si los límites son legítimos. Esta es una consecuencia directa del método de interpretación en dos etapas, culmina el análisis de la segunda de éstas, y permite delimitar la intervención solamente a una parte del derecho, y no a todo su contenido. ${ }^{71}$

Entre más severa sea la afectación al derecho, mayor será la justificación necesaria para legitimar esa restricción. La decisión sobre la constitucionalidad de los límites no es definitiva, sino que genera reglas de preferencia condicionada. ${ }^{72}$ Esto obedece a que la afectación producida al derecho dependerá de los elementos fácticos y jurídicos relevantes en cada caso, y es una característica de la lectura principialista de la Constitución.

Esto provoca un análisis casuístico forzoso que considera cuatro elementos: i) finalidad constitucionalmente legítima; ii) idoneidad; iii) necesidad, y iv) proporcionalidad en sentido estricto. ${ }^{73}$ En consecuencia, la variación de los factores relevantes en cada situación impide establecer reglas fijas para resolver casos futuros, pero sí permite establecer precedentes. ${ }^{74}$

Cada uno de estos elementos implica un análisis en sí mismo, porque analiza variables particulares. La restricción debe superar cada nivel de escrutinio progresivamente, de forma que si la restricción no supera el primer nivel de escrutinio - legitimidad constitucional— es innecesario continuar con el resto del análisis. En la misma tesitura, si la finalidad de la restricción es constitucionalmente legítima pero no idónea para alcanzarla, el análisis se detiene en ese punto.

Barcelona, Gedisa, 2004, p. 75; Klatt, Matthias y Meister, Moritz, op. cit., p. 10. También véase SCJN, Amparo directo en revisión 85/2014. Sentencia de la Primera Sala del 4 de junio de 2014, M.P. José Ramón Cossío Díaz, párrs. 34 y 35.

71 "Toda ley que afecte de manera negativa a una norma o a una posición que pueda adscribirse prima facie al ámbito de protección inicial de un derecho fundamental debe ser considerada como una intervención en ese derecho", Bernal Pulido, Carlos, op. cit., p. 838 .

72 Alexy, Robert, Teoría de los derechos fundamentales, cit., p. 136.

73 Barak, Aharon, Proportionality..., cit., p. 131; Klatt, Matthias y Meister, Moritz, op. cit., pp. 153 y ss; Bernal Pulido, Carlos, op. cit., pp. 874 y ss.

74 Garner, Bryan et al, The Law of Judicial Precedent, Minnesota, Thomson-West, 2016, pp. 21 y ss; Sunstein, Cass, Legal Reasoning and Political Conflict, 2a. ed., Nueva York, Oxford University Press, pp. 71 y ss. 


\section{Finalidad constitucionalmente legitima}

Aquí no se examina la constitucionalidad de restricción, sino de la finalidad que ésta persigue. ${ }^{75}$ Esto presupone que no cualquier finalidad justifica la restricción de un derecho. ${ }^{76}$

En el Amparo en Revisión 208/2016, la Primera Sala de la SCJN sostuvo que "[L]os fines que pueden fundamentar una intervención legislativa al ejercicio de los derechos humanos tienen muy diversa naturaleza: valores, intereses, bienes o principios que el Estado legítimamente puede perseguir". ${ }^{77}$ Por su parte, el pleno afirma que establecer restricciones al ejercicio de un derecho es legítimo cuando se busca proteger otro derecho humano o un principio constitucional. ${ }^{78}$

Para conocer la finalidad que persigue la restricción es útil acudir a la exposición de motivos y otros documentos que informan el proceso legislativo - Garner y Scalia son críticos de esta opción—, ${ }^{79}$ o el contexto normativo de la disposición en análisis. ${ }^{80}$

Una vez que se conoce la finalidad de la restricción, hay que examinar si tiene cobertura constitucional. Para ello, el operador jurídico puede valerse de la teoría de las normas sobre la producción o del test de escrutinio judicial.

De acuerdo con la teoría de las normas sobre la producción, existen dos formas de regularidad constitucional: regularidad formal y regularidad material. ${ }^{81}$ La primera determina las condiciones de existencia y vigencia de las normas, y depende de que la norma producida sea coherente con las normas formales sobre su producción; la segunda depende de la coherencia de la norma producida con las normas materiales sobre su producción.

En este sentido, para que la finalidad sea constitucionalmente legítima debe ser acorde a las normas materiales sobre la producción porque éstas

\footnotetext{
75 Barak, Aharon, Proportionality..., cit., p. 249.

76 SCJN, Amparo en revisión 208/2016, op. cit., p. 22.

77 Idem.

78 SCJN, Recurso de Revisión en Materia de Seguridad Nacional 1/2015, cit., pp. 34

y 35; Klatt, Matthias y Meister, Moritz, op. cit., p. 23.

79 Scalia, Antonin y Garner, Bryan, op. cit., pp. 369 y ss.

80 Barak, Aharon, Purposive Interpretation..., cit., pp. 148 y ss.; Breyer, Stephen, op. cit., pp. 151 y ss.

${ }^{81}$ Ferrajoli, Luigi, op. cit., pp. 51 y ss.
}

\footnotetext{
Esta obra está bajo una Licencia Creative Commons Atribución-NoComercial-SinDerivar 4.0 Internacional, IIJ-UNAM.
} 
se ubican en un plano normativo superior y delimitan el ámbito de lo que el legislador puede decidir o no. ${ }^{82}$

Por su parte, el escrutinio judicial puede ser ordinario o estricto. En el escrutinio ordinario, la finalidad debe ser constitucionalmente admisible; es decir, basta con que no esté constitucionalmente prohibida ${ }^{83}$ En el escrutinio estricto, la finalidad debe tener un apoyo constitucional claro u obedecer un mandato constitucional; es decir, debe ser constitucionalmente necesaria. ${ }^{84}$

La teoría de las normas sobre la producción y el test de escrutinio judicial no son excluyentes. De hecho, pueden utilizarse complementariamente o de manera individual. Aquí sólo quiero resaltar su utilidad para ilustrar si la finalidad que persigue una norma es constitucional.

En este sentido, si la constitución no protege al propósito de la restricción o lo prohíbe expresamente, el juicio de proporcionalidad se detiene.

Por ejemplo, la Primera Sala de la SCJN sostuvo que privilegiar el apellido paterno al asentar el nombre de los hijos persigue una finalidad inconstitucional. Esto obedece a que tradicionalmente el orden de los apellidos denota una posición de poder y estatus. Por ello, colocar primero el apellido del hombre perpetúa concepciones y prácticas que discriminan a la mujer, por considerar que es el nombre del padre el que debe transmitirse de generación en generación. ${ }^{85}$

Cuando la finalidad de la restricción es inconstitucional, no tiene sentido continuar con el análisis porque no puede analizarse la idoneidad, necesidad y proporcionalidad de una norma que persigue un fin inconstitucional. Sin embargo, si la finalidad perseguida tiene asidero constitucional, debe pasarse al estudio de idoneidad de la restricción.

\section{Idoneidad}

Una restricción es idónea si puede alcanzar la finalidad constitucional que persigue.$^{86}$ No es necesario que la restricción alcance totalmente o con

\footnotetext{
82 Ibidem, pp. 53 y ss.
}

83 SCJN, Acción de Inconstitucionalidad 8/2014. Sentencia del Pleno del 11 de agosto de 2015, M. P. Alfredo Gutiérrez Ortiz Mena, pp. 28 y 29.

84 Ibidem, p. 29.

85 SCJN, Amparo en Revisión 208/2016, cit., pp. 22-26.

86 Barak, Aharon, Proportionality..., cit., p. 303. Alexy, Robert, Teoría de los derechos fundamentales, cit., p. 94. 
certeza su finalidad constitucional. Basta que el grado de realización sea razonable, sin que esto implique trivializarlo.

De hecho, si partimos de una lectura principialista de la constitución, no puede asegurarse que una norma será plenamente operativa porque la eficacia de los principios es variable. Esto es algo que hasta un crítico del constitucionalismo principialista, como Ferrajoli, reconoce. ${ }^{87}$

Por ejemplo, la SCJN determinó que garantizar la eficacia de las Fuerzas Armadas es una finalidad constitucionalmente legítima. Sin embargo, el retiro forzoso basado en la inutilidad por seropositividad a los anticuerpos contra el VIH no es una medida idónea para alcanzar esa finalidad.

En efecto, los avances de la medicina demuestran que el desarrollo del VIH, y en última instancia del SIDA, no merma por sí mismo la capacidad de las personas para realizar las funciones requeridas por el ejército. ${ }^{88} \mathrm{De}$ esa manera, no había una relación de causa-efecto total o parcial entre garantizar la eficacia de las Fuerzas Armadas y el retiro forzoso de los elementos seropositivos, Por ello, la restricción no superó el test de idoneidad.

\section{Necesidad}

Una restricción es necesaria sólo si es la opción menos lesiva para alcanzar la finalidad que persigue ${ }^{89} \mathrm{El}$ test de necesidad tiene dos requisitos: i) ser la opción menos restrictiva, y ii) alcanzar, en la mayor medida posible, el propósito para el que fue creada. ${ }^{90}$ De este modo, una restricción no es necesaria si existen alternativas menos severas, y además pueden alcanzar con eficacia la finalidad que ésta persigue.

Para ser necesaria, una restricción debe: i) afectar lo menos posible al derecho humano; ii) tener el ámbito de restricción más acotado; iii) generar una afectación menos duradera, y iv) incidir en el menor número de personas posible..$^{1}$

87 "Es claro que semejante estructura del Estado constitucional de derecho está destinada, por su misma naturaleza, a un grado más o menos elevado de ineficacia...". Ferrajoli, Luigi, Derechos y garantías. La ley del más débil, 7a. ed., trad. de Perfecto Andrés Ibañez, Madrid, Trotta, 2010, p. 24.

88 SCJN, Amparo en revisión 1659/2006. Sentencia del Pleno del 27 de febrero de 2007, M. P. José de Jesús Gudiño Pelayo, pp. 89 y ss.

89 Alexy, Robert, Teoría de los derechos fundamentales, cit., pp. 93 y 94.

90 Barak, Aharon, Proportionality..., cit., pp. 323 y ss.

91 Nogueira Alcalá, Humberto, "El uso del postulado de proporcionalidad en la juris- 
Esto no significa que sea preferible pecar por defecto que por exceso. De hecho, una restricción es inútil si no puede alcanzar en la mayor medida posible el fin para el que fue creada. Sin embargo, el diseño normativo de una restricción a los derechos humanos debe optimizar - tanto como se pueda - la finalidad que persigue y — paralelamente - minimizar el grado de afectación al derecho restringido.

Por ejemplo, en el caso Kimel, la Corte IDH determinó que el derecho penal era excesivamente restrictivo para sancionar los daños producidos al derecho al honor, por el ejercicio de la libertad de expresión. Así, la Corte IDH concluyó que el uso del poder punitivo del Estado fue excesivo, ${ }^{92}$ pues las acciones del señor Kimel no merecían una sanción penal porque no eran extremadamente graves, dolosas, ni producían un daño injusto. ${ }^{93}$

De hecho, en su voto particular, el Juez García Ramírez sostuvo que, por la vía civil se podrían obtener los mismos resultados que por la vía penal, porque representa una declaración de ilicitud igualmente enfática, sin afectar más de lo necesario el derecho a la libertad de expresión. ${ }^{94}$

\section{Proporcionalidad en sentido estricto}

Aquí se valora si optimizar la finalidad de la restricción - D2 o BCjustifica el límite a D1. Para ello, el derecho y la finalidad de la restricción no se analizan en abstracto. Esto se consideró al determinar el alcance de D1 en la primera etapa; aquí el estudio es concreto, en relación con los hechos del caso, ${ }^{95} \mathrm{y}$ es una consecuencia directa del modelo interpretativo en dos etapas.

El test de proporcionalidad en sentido estricto valora los hechos en relación con: i) el grado de afectación al derecho restringido; ii) la relevancia constitucional del principio o derecho contrario, y iii) si la optimización

prudencia de la Corte Interamericana de Derechos Humanos sobre libertad de expresión”, Estudios Constitucionales, año 9, núm. 1, 2011, p. 122.

92 Corte IDH, Caso Kimel vs. Argentina. Fondo, reparaciones y costas. Sentencia del 2 de mayo de 2008, serie C, núm. 177, párr. 80.

93 Ibidem, párr. 78.

94 "Voto concurrente del juez Sergio García Ramírez", en Corte IDH, Caso Kimel vs. Argentina, cit., párr. 21.

95 Barak, Aharon, Proportionality..., cit., p. 352; Silva Meza, Juan y Silva García, Fernando, op. cit., p. 303. 
de la finalidad justifica la restricción del derecho. ${ }^{96}$ Así, no hay una regla para todos los casos que relegue al principio pro persona al ostracismo interpretativo; por el contrario, esto exige su utilización en cada caso para determinar la legitimidad de la restricción.

El resultado del juicio de proporcionalidad es una respuesta individualizada. Ésta sólo resuelve el caso concreto - o una clase de casos-, pero puede cambiar frente a hechos y factores jurídicos distintos. ${ }^{97}$

Por ejemplo, en Kimel vs. Argentina, la Corte IDH no valoró en abstracto si la protección de la honra justifica sancionar penalmente el ejercicio de la libertad de expresión, sino la proporcionalidad de las consecuencias de la sanción impuesta al señor Eduardo Kimel.

En el Recurso de revisión en materia de seguridad nacional 1/2015, el pleno no consideró si el principio de seguridad nacional puede derrotar el derecho al acceso a la información pública. Lo que la SCJN consideró fue la posibilidad de comprometer la capacidad de respuesta del Estado frente al crimen organizado, y la seguridad de la aviación, de pasajeros y tripulantes por divulgar las rutas de las aeronaves del Estado Mayor Presidencial.

Este análisis concluye la interpretación en dos etapas. En efecto, en la primera etapa se determina el contenido previo del derecho humano —al margen de potenciales restricciones_- en la segunda, se determina el alcance de los bienes jurídicos que afectan el contenido previo, y si esa afectación tiene justificación constitucional. De esta manera, es posible garantizar — en todo momento - la protección más amplia.

\section{CONCLUSIONES}

El principio pro persona orienta la interpretación de los derechos humanos reconocidos por el parámetro de control de regularidad constitucional. Esto obedece a que, para poder otorgar la protección más amplia a los derechos de las personas, los operadores jurídicos deben interpretarlos de manera extensiva.

\footnotetext{
96 Corte IDH, Caso Kimel Vs. Argentina, cit., párr. 84; Alexy, Robert, Teoría de los derechos fundamentales, cit., p. 138.

97 Alexy, Robert, Teoría de los derechos fundamentales, cit., p. 146; cfr. Garner, Bryan et al., op. cit., pp. 21 y ss.; Sunstein, Cass, op. cit., pp. 71 y ss.
} 
Para ello hay que distinguir entre el contenido previo y el contenido definitivo de los derechos humanos. El primero abarca las conductas que el derecho protege en abstracto, y el segundo el alcance de esa protección a la luz del caso concreto.

Esta distinción propicia que el operador jurídico determine el contenido previo de los derechos en los términos más amplios posibles. En efecto, al trasladar hasta la segunda etapa cualquier consideración fáctica o jurídica relacionada con el caso, el contenido previo abarca la zona de certeza y la zona de penumbra del derecho.

Lo anterior evita que el análisis prematuro de los elementos jurídicos relevantes cercene el contenido previo del derecho, y optimiza su alcance en sede interpretativa.

Esta concepción del principio pro persona se aproxima considerablemente a la teoría principialista de los derechos humanos de Robert Alexy. Desde esta óptica, los derechos humanos son mandatos de optimización que deben realizarse en los términos más amplios posibles, de conformidad con los elementos fácticos y jurídicos relevantes. Es decir, normas que por su propia naturaleza deben interpretarse extensivamente.

De allí que yo afirme que cuando la CPEUM exige la protección de los derechos humanos en los términos más favorables, en realidad los está transformando en normas con la estructura de principios.

Esto tiene dos implicaciones. La primera es que el juicio de proporcionalidad sería el método para resolver los conflictos entre el alcance de dos derechos o entre un derecho y un bien jurídico protegido de relevancia constitucional. La segunda sería que, las restricciones constitucionales ya no tengan una presunción de validez absoluta a priori y, en consecuencia, el principio pro persona irradie sus efectos sobre todo el parámetro de control de regularidad constitucional.

Fecha de recepción: 23 de octubre de 2018.

Fecha de dictamen: 14 de mayo de 2019. 